\title{
Comportamento informacional de gestores da rede Hiperdia Minas
}

Ricardo Bezerra Cavalcante

Enfermeiro, Doutor em Ciência da Informação, Pós-Doutorado em Ciência da Informação/ECI/UFMG, Núcleo de Estudos e Pesquisas em Avaliação e Gestão de Serviços de Saúde da Universidade Federal de São João Del Rei (NEPAG/UFSJ), Divinópolis (MG), Brasil

Yoshimi José Ávila Watanabe

Médico nefrologista e Cientista da Computação. Mestre em Biotecnologia pelo Programa de Pósgraduação em Biotecnologia da Universidade Federal de São João Del Rei (PPGBiotec-UFSJ)

Eliete Albano de Azevedo Guimarães

Enfermeira, Doutora em Ciências da Saúde, Núcleo de Estudos e Pesquisas em Avaliação e Gestão de Serviços de Saúde da Universidade Federal de São João Del Rei (NEPAG/UFSJ), Divinópolis (MG).

Tarcísio Laerte Gontijo

Enfermeiro, Doutor em Ciências da Saúde, Núcleo de Estudos e Pesquisas em Avaliação e Gestão de Serviços de Saúde da Universidade Federal de São João Del Rei (NEPAG/UFSJ),Divinópolis (MG).

Valéria Conceição de Oliveira

Enfermeira, Doutora em Enfermagem, Núcleo de Estudos e Pesquisas em Avaliação e Gestão de Serviços de Saúde da Universidade Federal de São João Del Rei (NEPAG/UFSJ),Divinópolis (MG).

Daniela Dias Vasconcelos

Enfermeira. Mestranda em Enfermagem no Programa de Pós-graduação em Enfermagem da Universidade Federal de São João Del Rei. Especialista em Atenção Básica/Saúde da Família. Núcleo de Estudos e Pesquisas em Avaliação e Gestão de Serviços de Saúde da Universidade Federal de São João Del Rei (NEPAG/UFSJ), Divinópolis (MG). 
Trata-se de um estudo de caso de abordagem qualitativa que buscou analisar o comportamento informacional de gestores da rede Hiperdia Minas em relação ao cotidiano de trabalho. Entrevistas semiestruturadas foram realizadas com 10 gestores da rede. A Técnica do Incidente Crítico foi utilizada durante as entrevistas compondo o roteiro semiestruturado. Para a análise dos dados utilizou-se como referencial a Análise de Conteúdo. O software Atlas $\mathrm{Ti}$ foi utilizado para sistematizar a análise. Necessidades informacionais, fontes, processo de busca, análise, disseminação de informações e tomada de decisões no cotidiano dos serviços sofrem influências das normativas e burocratizações que regem o programa. Emergiram também situações que afetam 0 comportamento informacional dos gestores. Logo, o comportamento informacional na rede Hiperdia Minas necessita ser organizado e administrado com vistas ao reconhecimento da informação como um recurso potencial de mudanças e de gestão qualificada.

Palavras-chave: Informação; Informação em Saúde; Comportamento Informacional; Gestão da Informação.

\section{The manager information behavior of Hiperdia program of Minas Gerais state}

It is a case study of qualitative approach that analyzed the manager information behavior of Hiperdia program of Minas Gerais' according to the diary work. Semi structured interviews were carried out with 10 web managers by using the critical incident technique. The data were analyzed using as reference the content analysis. The Atlas Ti software was used to systematize the analysis. Information needs, searching process, analysis, dissemination of the information and decisionmaking at the diary works undergo influence of regulation and bureaucracy. Other factors affecting the information behavior of managers were also observed. Therefore, the information behavior of Hiperdia program in Minas Gerais 
needs to be organized and managed in order to reach the knowledge of information as a potential source of changes and management of quality.

Keywords: Information; Information in health; Information behavior; Management information system.

Recebido em 04.03.2016 Aceito em 13.07.2017

\section{Introdução}

Diante do grande volume de dados gerados emerge o desafio de buscar, selecionar, analisar e entender o conjunto de informações dispersas transformando-as em conhecimentos e decisões assertivas (BYYNY, 2012). Estas atitudes constituem o comportamento informacional que envolve aspectos humanos relacionados à informação, sendo necessária a sua administração (WILSON, 2000). Desse modo, o comportamento informacional consiste numa forma de agir do indivíduo em uma determinada situação, impulsionado por necessidades incentivadas, voluntárias ou pela necessidade da edificação do conhecimento (AKAICHE et al., 2013). Para Gasque e Costa (2010) o comportamento informacional é todo comportamento humano que tem analogia com a informação, tais como a busca passiva e ativa, usos de fontes e canais de informação.

Wilson (2000) descreve e identifica, ainda, possíveis apresentações para o termo "Comportamento Informacional" como, o comportamento informacional propriamente dito, o comportamento de busca da informação, de busca e pesquisa de informações e por último o comportamento de uso da informação. O primeiro, o comportamento informacional é a totalidade do comportamento humano em relação às fontes e canais de informação. A segunda descrição, o comportamento de busca da informação é a busca intencional de informações como consequência de uma necessidade de satisfazer algum objetivo. O terceiro conceito refere-se ao comportamento de busca e pesquisa de informações que é o ato empregado pelo pesquisador na interação com sistemas de informação de todos os tipos. Por fim, o comportamento de uso da informação constitui o conjunto dos atos físicos e mentais e abrange a incorporação da nova informação aos conhecimentos prévios do indivíduo.

Nogueira e Neves (2009) em um estudo sobre comportamento informacional na área da saúde, no Brasil, apontam para a necessidade de práticas de gestão da informação mais sistemáticas e que proporcionem suporte a gestão e a assistência à saúde. Além disso, as necessidades informacionais nos serviços de saúde são geralmente determinadas por programas governamentais que preconizam a pactuação de metas e avaliação de indicadores; e com isso os serviços tendem a restringir as 
buscas nas bases dos sistemas de informações, manuais e opiniões de profissionais experientes (MARTÍNEZ-SILVEIRA; ODDONE, 2007).

Um estudo realizado por Albini e Filho (2015), envolvendo gestores de hospitais universitários, verificou que esses recorriam ao uso da informação no processo de tomada de decisão; permaneciam rodeados por inúmeras informações; as informações disponíveis tinham atributos de qualidade contestáveis; os gestores tomavam decisões embasados em informações aproximadas (sob risco); a conjuntura política, os aspectos legais e a complexidade da área saúde pública dificultavam a tomada de decisão; os gestores partilhavam informações com suas equipes para tomar decisões; o alicerce fundamental para tomada de decisões pelos gestores foi a sua experiência prévia; o principal nível de decisão tomada pelos gestores da unidade funcional foi de caráter gerencial; houve falta de autonomia administrativa no processo decisório das unidades funcionais.

A maioria dos estudos sobre comportamento informacional, na área da saúde, abordam os profissionais de saúde e pacientes, porém percebese a carência de pesquisas que abordem "o corpo administrativo" que envolve a área (EK, 2015; PATEL; DOWSE, 2015). É importante entender o comportamento informacional também dos gestores, pois estes influenciam a assistência ao paciente e direcionam projetos e comportamentos dos profissionais de saúde, que lidam diariamente com o paciente na rede de atenção em saúde, principalmente envolvendo o Sistema Único de Saúde (SUS).

Inúmeras são as áreas de atuação profissional em que a informação e o conhecimento são utilizados como base nos processos decisórios. Na saúde isso não é diferente (LONG; CURTIS, 2015; ZARDO; COLLIE, 2015). Em especial, a assistência ao paciente crônico demanda uma estrutura e uma organização da rede de atenção que deve estar preparada para prestar suporte e cuidados aos doentes. Neste sentido os gestores são atores essenciais na transformação de informações em conhecimentos e decisões assertivas, o que pode aumentar a capacidade de resposta e inovação dos serviços. A produção de conhecimentos sem a sua aplicabilidade na prática não tem qualquer impacto sobre a saúde das pessoas (CANADIAN INSTITUTES OF HEALTH RESEARCH - CIHR, 2012).

Neste contexto, aponta-se a seguinte questão norteadora: "Como se dá o comportamento informacional de gestores no Programa Hiperdia Minas? Trata-se de um programa governamental criado em 2010 pela Secretaria Estadual de Saúde de Minas Gerais (SES/MG) (MINAS GERAIS, 2010). Sabe-se que o programa busca identificar, tratar e acompanhar pacientes que possuem hipertensão e diabetes com suas variantes de complicação clínica. O Programa Hiperdia Minas já tem assistido quase um quarto da população do estado de Minas Gerais e projeta atingir mais de 20 milhões de mineiros que possuem patologias crônicas como Hipertensão, Diabetes e Doença Renal nos próximos anos, ampliando sua cobertura (MINAS GERAIS, 2014). 
Sabedores de que a informação, no programa Hiperdia, perpassa a complexa rede hierarquizada constituída pela SES/MG, a Secretaria Municipal de Saúde (SMS), a Superintendência Regional de Saúde (SRS/MG) e os Centros Hiperdia Minas (CHDM) e que a aplicação do conhecimento produzido pode contribuir para o sucesso ou o fracasso do programa, justifica-se a necessidade deste estudo. Enfim, o uso eficiente da informação entre gestores de um programa importante do governo estadual na área de saúde é por si só, um motivador e norteou o desenvolvimento desta pesquisa que teve como objetivo analisar 0 comportamento informacional de gestores da rede Hiperdia Minas em relação ao cotidiano de trabalho.

\section{Panorama conceitual e teórico}

As diversas profissões, seja no campo das ciências exatas, ciências humanas e ou da saúde, estão sujeitas a mudanças que afetam diretamente a vida cotidiana. No cenário atual com a rápida e crescente evolução da tecnologia e a velocidade de demanda, novas exigências estão sendo criadas. Novos perfis profissionais estão sendo gerados. Lidar com esses desafios impostos, atender as necessidades apresentadas e responder prontamente aos desafios expostos, fez com que a forma de se captar, entender e processar a informação, gerasse a necessidade de se entender melhor a questão: Necessidade informacional e/ou o Comportamento Informacional (TAGA; BLATTMAN, 2012).

Outros aspectos a serem destacados envolvem papéis $\mathrm{e}$ competências desempenhadas pelo gestor, que é um líder gerencial e devem abranger requisitos necessários para que haja desenvoltura, agilidade, credibilidade e eficiência nas tomadas de decisões (SCHAEFER, 2005). Neste ambiente inóspito, a confiança dos seus comandados e a sua credibilidade devem ser impostas como requisitos de liderança (HESSELBEIN; GOLDSMITH; BECKARD, 1996) para que as organizações ganhem força e atinjam seus objetivos.

Martínez-Silveira (2005) propõe que se diferencie a chamada Necessidade Informacional do Comportamento Informacional e descreve que a necessidade informacional pode ser entendida como uma experiência subjetiva que ocorre na mente de cada indivíduo em determinada circunstância ou como condição objetiva observável quando uma informação específica contribui para atender ao motivo que a gerou. Comportamento informacional, em contrapartida, está relacionado à busca, ao uso e ao manejo de informações e fontes para satisfazer aquelas necessidades (MARTÍNEZ-SILVEIRA, 2005).

Na última década, observa-se mudanças consideráveis no contexto de Comportamento Informacional, abrindo-se uma nova perspectiva para se entender o que se chama: Competência, Necessidade, Orientação e ou Comportamento Informacional. Os diversos termos se inter-relacionam e são tratados em diferentes meios científicos e em perspectivas próprias dentro da sua óptica (MIRANDA, 2004) 
Wilson (2000) define, no modelo revisado e descritivo de comportamento informacional, que em um contexto de necessidade, uma pessoa diante de um problema, por exemplo, tenta resolvê-lo. Esta pessoa que vive, trabalha em um ambiente geograficamente definido, sofre interferência de outras variáveis, denominadas intervenientes, como seu estado psicológico e a sua capacidade de relacionamento, quanto é ativado o seu mecanismo de busca por soluções. Após filtrar e selecionar suas informações, esta pessoa realiza o seu processamento e ou o seu uso.

Para Choo (1999) a busca da informação ocorra em três níveis distintos e principais: a necessidade da informação, a busca da informação e o uso da mesma. E que em cada nível ou camada outros três fatores permeiam este processo: os afetivos, os cognitivos e os situacionais. Como fatores cognitivos destaca-se a personalidade e as preferências pessoais na escolha. $O$ afetivo depende dos estados emocionais envolvidos e o situacional é modulado por questões normativas, de regras de profissão e organização em que o indivíduo está inserido.

Para Choo (1999), vários motivos podem justificar a necessidade de informação, destacando os afetivos como a carência de sentido, de entendimento levando a um estado de incerteza, ambiguidade, frustração, ansiedade e a falta de confiança. Estes fatores emocionais podem ser influenciados por questões pessoais e dependem das habilidades também individuais para resolver as necessidades informacionais, desencadeando ações de busca.

Entendendo como atividade de busca, descrita por Choo (1999), o nível secundário neste escalonamento do modelo de comportamento informacional, a procura por informação ocorre, quase sempre, na tentativa de resolver problemas ou encontrar soluções nos processos de tomada de decisão nas esferas organizacionais. Nesta etapa, ocorre a identificação e a seleção das fontes, referências que dependendo da sua qualidade, confiança e relevância, passa a considerar o seu uso nas decisões, por exemplo.

A terceira camada descrita por Choo (1999) sugere que o uso da informação depende dos outros fatores descritos como a necessidade e a busca, mas que pode ser afetado pelas mesmas questões relacionadas, as cognitivas, afetivas e situacionais. O indivíduo diante de uma necessidade de informação pode escolher e tomar a decisão de três maneiras: evitar, desconsiderar ou encarar o problema. Evitar o problema seria o mesmo que suprimir esta necessidade. Desconsiderar ou ignorar não despertaria qualquer atividade desencadeadora de busca de informações para se solucionar uma questão. A terceira via, desperta o processo de busca, constituindo assim, no comportamento informacional.

Diante dos fatores descritos de cada uma das fases do comportamento informacional, o autor propõe a integração das três fases. Nesta revisão de modelo de comportamento informacional, Choo (1999) propõe que diante de necessidades de informação, indivíduos podem, dependo da sua experiência e vivência decidir por evitar o problema, 
desconsiderar que ele exista ou confrontar. Fatores como o entendimento, percepção e capacidade de conceber a dimensão do problema, interferem neste processo. A busca pela informação desencadeada pelo interesse despertado, promove a curiosidade e a sua atitude de tentar entender o evento ou fato. Nesta camada, a qualidade da fonte, a sua acessibilidade e disponibilidade são cruciais para o sucesso. Considerando que este ato envolve pessoa, o interesse e a motivação devem ser destacados. Se não existir interesse nem motivação para fazê-lo, a busca não ocorrerá. Feito a coleta de informações, passa-se ao que se pode chamar de processamento e análise dos dados. Analisadas as possibilidades de solução ou encaminhamento do "problema" o indivíduo pode tomar decisão. Diante de informações processadas e analisadas, o passo seguinte se faz presente, o uso da informação.

Usar a informação permite a escolha de opções como agir, negar ou ficar indiferente ao fato. A tomada de decisão passa por todas as etapas descritas e a sua conclusão deve ser permeada por entender as atividades cognitivas, as regras e normas para a sua aplicabilidade. Avaliar o momento em que ele vai ser aplicado, considerando estas variáveis, também é importante. Assim seriam desencadeadas uma sucessão de ações, diante de um problema. Este seria o comportamento informacional no modelo integrado de Choo (1999).

A evolução dos estudos de comportamento que envolvem usuários no trato da informação sofrera mudanças com o passar dos tempos. Desde o século passado estudiosos descreviam e separavam "estudos de usuários" de "comportamento informacional de usuários" (GASGUE; COSTA, 2010). As pesquisas concentravam ora nos indivíduos, ora nos meios empregados nos processos de uso da informação.

Durante este período do passado, foram depositadas energias nos estudos dos sistemas, preocupando-se mais com o funcionamento dos mecanismos e com a recuperação e acesso a informação (MARTÍNEZSILVEIRA, 2005). Havia uma fragmentação nas pesquisas que abordavam a necessidade de informação dos usuários (GASGUE; COSTA, 2010). Gradativamente os pesquisadores incorporaram outras preocupações que se tornaram emergentes, vinculando aspectos psicológicos e situacionais, principalmente com o número de publicações que abordavam o tema que continuava em crescimento constante.

Na década de noventa, Wilson (1997) e Kuhlthau (1991) passaram a orientar seus estudos sob o ponto de vista cognitivo, reconhecendo que as necessidades de informação ocorrem neste campo. Passaram a pesquisar e conhecer as características de cada usuário e o processo cognitivo envolvido. Abordaram questões como categorização técnica, aprendizagem, memórias, motivações tipos de personalidades e fatores semânticos (GASGUE; COSTA, 2010).

Posteriormente, em estudos contemporâneos, o núcleo central passou a ser o usuário. A ênfase passa a ser aplicada nas interações entre os contextos cognitivos, sociais, culturais, afetivos, linguísticos, 
organizacionais em que o comportamento informacional é parte integrante do processo de comunicação do ser humano. (GASGUE; COSTA, 2010).

A ética da responsabilidade suscita o desafio de desempenhar um papel estruturante em uma área de crescente importância estratégica no âmbito do setor saúde, pois, no cenário contemporâneo, a informação e as tecnologias a ela referidas possuem tal centralidade e relevância que sua excelência ou precariedade afeta o desenvolvimento de cada área de atividade social, a obtenção de seus objetivos e dos resultados desejados. A gestão da Informação e suas tecnologias tornam-se, assim, macrofunção estratégica da gestão do SUS (GTISP; ABRASCO, 2013).

Os estudos sobre o comportamento informacional foram demarcados a partir dos anos quarenta do século passado, mais precisamente em 1949 (TAGA; BLATTMAN, 2012). A tentativa inicial era a de demonstrar as vantagens do compartilhamento das descobertas científicas. No período pós-guerra as pesquisas eram centradas nas áreas do conhecimento e nas questões voltadas aos estudos de usuários. Apenas na década de setenta, temas que apontavam relacionamentos entre pessoas, problemas e necessidades foram descritos. Posteriormente, na década de oitenta, os sistemas de informação e as pesquisas foram incorporadas aos estudos e voltadas para a recuperação de informação e seu armazenamento (MARTÍNEZ-SILVEIRA; ODDONE, 2007). A partir desta década, surgem estudos centrados no usuário e nos seus atributos individuais e psicológicos. As pesquisas na área passam a ser estudados com foco qualitativo. Assim, Wilson a partir da década de 90, utiliza mais amplamente a terminologia "comportamento informacional", contemplando as questões de "busca", "uso" e "necessidade de informação", incorporando conceitos sobre a necessidade e oferta da informação (TAGA, BLATTMAN, 2012).

Apesar de Davenport (1998) não propor um modelo de comportamento informacional, ressalta a necessidade de que o mesmo seja administrado nas organizações. O autor entende que a busca, o uso, a alteração, a troca, o acúmulo e o ato de ignorar a informação compreendem etapas do comportamento informacional, sendo fortemente influenciados pela cultura organizacional e a cultura informacional. Em seus estudos propõe algumas táticas para gerenciar o comportamento informacional, são elas: os funcionários de uma empresa devem ser convencidos do valor da informação e por isso a sua finalidade e significado devem ser disseminadas; a organização deve tornar clara as suas estratégias de informação, definindo as metas a serem alcançadas por intermédio da informação; as competências informacionais necessárias para o desenvolvimento das atividades dos profissionais devem ser mapeadas, bem como fortalecidas; criar equipes de profissionais responsabilizados pela administração do comportamento informacional e pela gestão da informação; instruir os profissionais no trato com a informação; proporcionar uma cultura informacional onde se valoriza e organizam os fluxos informacionais. 
Entretanto, França (2002), ao estudar o Comportamento Informacional de profissionais do Programa Saúde da Família (PSF), verificou que há preferências entre os agentes comunitários de saúde, por fontes pessoais, pelas reuniões comunitárias e pelos contatos face a face com colegas do PSF, sendo constatado que não frequentavam bibliotecas nem acessavam, as informações eletrônicas disponibilizadas pelo Ministério da Saúde e DATASUS. Outra constatação foi a indisponibilidade de meio físico, computador, nas unidades básicas de saúde.

Nogueira e Neves (2009), analisando equipes de saúde da família, constataram que há uma carência de informação e também um desconhecimento por parte dos gestores destes serviços para com a sua realidade, existindo uma dissonância entre a compreensão pelos profissionais acerca da informação e a sua disponibilidade de fato. Segundo os autores, faltam informações e organização estrutural entre os níveis de gestão para que as ações possam ser melhor exercidas. Neste estudo foi apontada a necessidade de um gestor da informação (que fosse da equipe) e uma aproximação maior entre os níveis de gerência e coordenação do programa. Sugerem ainda, que a coordenação desempenhe um papel mais importante no que se refere ao processamento da informação por se tratar do principal órgão gestor dentro do PSF no município, pois são responsáveis pela criação de diretrizes e normas.

No estudo de Santos (2011) verificou-se que os participantes realizaram as buscas dos dados em sistemas que continham bases de dados do SUS. Esta busca fora considerada satisfatória e atendia as necessidades apontadas. Outra constatação do estudo apontou que a principal fonte de busca de informações foi o coordenador regional, confirmando a referência interpessoal. O pesquisador sinalizou para uma necessidade de criação de uma rede informacional, em que, se apresente como base e que permita a pesquisa com recursos disponíveis, possibilitando aos trabalhadores conhecimento para o uso de estratégias e soluções das necessidades de informações.

Outro estudo, realizado por Rodrigues (2009), com conselheiros de saúde, evidenciou barreiras para buscar informações nos meios em que eles viviam. Estes impedimentos eram apontados como, por exemplo, as limitações dos conselheiros na busca da informação quanto ao uso das tecnologias disponíveis até a acessibilidade às fontes. Nestes casos eram feitas consultas pessoais e a instâncias superiores e em reuniões. Entre as propostas do estudo, surgiu a recomendação de se disponibilizar dados utilizando as tecnologias de informação (redes sociais e sites) com conteúdo específico, voltado para o armazenamento e possibilitar a distribuição das informações necessárias para a sua atividade de conselheiro de saúde. 


\section{A rede Hiperdia Minas como o ambiente de pesquisa}

A rede de atenção à saúde (RAS) e de serviços integrais e integrados são considerados fundamentais dentro da forma de organização e cuidado à saúde (MENDES, 2011; ORGANIZAÇÃO PANAMERICANA DE SAÚDE, 2010). Esta organização permite que a assistência a pacientes com Hipertensão e Diabetes se concentre nos Centros Hiperdia Minas (CHDM) num ponto estratégico na abordagem secundária de nível assistencial, inter-relacionando-se com os níveis primários e terciários, amparados por um complexo sistema de apoio e logística.

A Rede assistencial de Hipertensão Arterial e de DM no estado de MG é organizada segundo um modelo de cascata e hierarquia de atenção à saúde dispostos em níveis de necessidades primárias, secundárias e terciárias. O nível terciário é composto por hospitais macrorregionais, sendo referenciados pelos níveis secundários, que comportam os hospitais microrregionais sem Unidade de Tratamento Intensivo (UTI), unidades especializadas em endocrinologia, serviços de reabilitação, unidades básicas em atenção cardiovascular, Serviço de Atendimento Médico de Urgência (SAMU), unidades especializadas em Odontologia, unidades especializadas em Nefrologia (sendo que estas duas últimas fazem interposição entre o nível terciário e secundário).

O Centro Hiperdia Minas (CHDM) encontra-se localizado no nível secundário de assistência e Sistema de Apoio e Logística da Secretaria Estadual de Saúde de Minas Gerais (SES/MG). As unidades de Atenção Primária de Saúde estão alocadas no nível primário de atendimento. Sendo assistidos por um complexo sistema de apoio e logística que conta com: transporte sanitário, prontuário eletrônico, cartão SUS, apoio diagnóstico, apoio farmacêutico e sistemas de informação (MINAS GERAIS, 2010).

Dentro deste grande programa, nota-se a existência de uma cidade sede, onde localiza fisicamente o Centro Hiperdia Minas (CHDM). Estes centros estão organizados e coordenados por fundações ou consórcio de cidades circunvizinhas ou de forma autônoma. Cada um dos CHDM têm a referência técnica ligada a sua cidade sede, através da Secretaria Municipal de Saúde (SMS) e a uma Superintendência Regional de Saúde (SRS) da sua região, com isso pode-se ter um Centro em uma cidade e a sua referência regional estar localizada em outra. Encontrando-se assim a denominação de Rede Hiperdia Minas, constituída pelo CHDM, a Secretaria Municipal de Saúde (SMS), a Superintendência Regional de Saúde (SRS) e a Secretaria Estadual de Saúde (SES/MG). 


\section{Método}

Trata-se de um estudo de caso de abordagem qualitativa. A justificativa pelo uso da pesquisa qualitativa se dá pela necessidade de entender e explicar um comportamento humano e os significados atribuídos pelos sujeitos às suas ações, sendo que para entender esses significados é preciso contextualizá-Ios (MINAYO, 2012). A escolha do estudo de caso como referencial metodológico, se deu pela sua capacidade de captar os acontecimentos contemporâneos e por preservar as características holísticas e significativas dos eventos da vida real (YIN, 2015). Neste caso a unidade de análise é o comportamento informacional de gestores em um programa governamental, o Hiperdia Minas.

Como referencial teórico-analítico utilizou-se o modelo conceitual de comportamento informacional de Wilson (2000) composto pelas seguintes dimensões: necessidades de informação que surgem por inquietações, sejam elas internas ou externas ao indivíduo, da relação do indivíduo com seu meio de inserção; busca pela informação que é a busca intencional em fontes de informação como consequência da necessidade de satisfazer algum objetivo; análise e uso da informação, que consiste na física e nos atos mentais envolvidos na incorporação da informação encontrada no conhecimento existente da pessoa, bem como sua avaliação sistemática; disseminação das informações, na perspectiva do compartilhamento, onde há trocas voluntárias de informações no fluxo informacional. A partir deste modelo foram identificadas as categorias de análise: necessidades informacionais, busca e fontes de informação; disseminação, análise das informações e uso das informações na tomada de decisões.

O cenário do estudo foi a rede que compõe o Programa Hiperdia no estado de Minas Gerais em suas esferas de gestão (estadual, regional e municipal). A SES/MG foi escolhida por ser o cenário de administração geral do Programa Hiperdia Minas. O CHDM localizado no município de Santo Antônio do Monte foi escolhido, dentre os 15 centros existentes em Minas Gerais, intencionalmente, por ser de fácil acesso aos pesquisadores. Assim, ambos, SMS de Santo Antônio do Monte e a SRS, referência do município citado, também foram escolhidos como pontos da rede.

A seleção dos participantes nos cenários obedeceu aos seguintes critérios de inclusão: (1) Gestores da SES/MG, representados pelos profissionais que fazem a coordenação do Programa Hiperdia Minas; (2) Gestor da SRS, a referência técnica do Programa Hiperdia; (3) Gestor municipal lotado na SMS de Santo Antônio do Monte responsável pelo programa nesta instância; e (4) Gestor do CHDM de Santo Antônio do Monte em atividade no ano de 2014.

A partir dos critérios anteriores foram incluídos 10 participantes dos 11 possíveis. Um gestor não participou do estudo, alegando indisponibilidade. Realizaram-se entrevistas semiestruturadas com os participantes. Desta forma, o roteiro constituiu-se de questões subdividas com três focos principais: a primeira, a caracterização do gestor e seu cotidiano de trabalho; a segunda, o seu comportamento e as atividades de 
trabalho e por último destinou-se a mensurar o comportamento informacional. O período de realização das entrevistas ocorreu entre os meses de setembro e dezembro de 2014. As entrevistas foram previamente agendadas, audiogravadas, transcritas e codificadas pela letra "P" seguida do numeral.

Em caráter complementar também se utilizou da Técnica de Incidente Crítico no roteiro de entrevistas (FLANAGAN, 1954). Nos moldes da referida técnica foram incluídos questionamentos no roteiro de entrevistas, onde se estimulou os entrevistados a lembrar de problemas e as formas que encontraram para resolvê-los a partir de decisões embasadas em informações. O Quadro 1 sintetiza o processo de elaboração do roteiro semiestruturado.

Quadro 1 - Processo de elaboração do roteiro semiestruturado utilizado no estudo

\begin{tabular}{l|l|l}
\hline $\begin{array}{c}\text { Partes do } \\
\text { Roteiro }\end{array}$ & Elementos mensurados & \multicolumn{1}{|c}{ Itens questionados } \\
\hline \hline Primeira Parte & $\begin{array}{l}\text { Caracterização dos } \\
\text { gestores }\end{array}$ & $\begin{array}{l}\text { Cargo, setor de trabalho, idade, vinculo, } \\
\text { formação, mobilidade setorial }\end{array}$ \\
\hline Segunda Parte & $\begin{array}{l}\text { Cotidiano de trabalho e e } \\
\text { comportamento } \\
\text { informacional a partir do } \\
\text { Modelo de Wilson (2000) }\end{array}$ & $\begin{array}{l}\text { Atividades desenvolvidas no cotidiano de } \\
\text { trabalho; planejamento das atividades, } \\
\text { equipe de trabalho, fontes de informações, } \\
\text { avaliação das informações, busca de } \\
\text { informações, compartilhamento de } \\
\text { informações, tomada de decisões a partir de } \\
\text { informações }\end{array}$ \\
\hline Terceira Parte & $\begin{array}{l}\text { Realização da Técnica } \\
\text { do Incidente Crítico para } \\
\text { mensurar } \\
\text { Comportamento } \\
\text { informacional }\end{array}$ & $\begin{array}{l}\text { O comportamento informacional diante de } \\
\text { umproblema vivenciado pelo entrevistado }\end{array}$ \\
\hline
\end{tabular}

Fonte: Elaborado pelos autores.

Os dados coletados foram analisados por meio da Análise de Conteúdo, modalidade Temático-Categorial, conforme Quadro 2 (BARDIN, 2011).

Quadro 2 - Etapas da Análise de Conteúdo modalidade TemáticoCategorial

\begin{tabular}{l|l}
\hline \multicolumn{1}{c|}{ Etapa } & \multicolumn{1}{|c}{ Descrição } \\
\hline \hline "Leitura flutuante" & $\begin{array}{l}\text { Primeiro contato com o texto a ser analisado e um } \\
\text { alinhamento mais preciso dos objetivos do estudo. }\end{array}$ \\
\hline Formulação do hipóteses e & $\begin{array}{l}\text { Recorte do texto, denominadas unidades de registro, e foram } \\
\text { elaboração de indicadores } \\
\text { codificados. As unidades de registro selecionadas fizeram } \\
\text { parte do corpus para a análise e seguiu as regras de } \\
\text { exaustividade, representatividade, homogeneidade e de } \\
\text { pertinência. }\end{array}$ \\
\hline
\end{tabular}


Transformação

Seguiram regras específicas para tratar o texto bruto e realizar a abstração de representações do conteúdo que permitiu a análise das expressões acerca das características relatadas.

Tratamento dos dados, das inferências e interpretações

Classificação dos elementos que compuseram as categorias finais por convergência das unidades de contexto.

Fonte: BARDIN (2011).

Com vistas a sistematizar a organização e análise dos dados utilizou-se o software Atlas Ti.

Este estudo obedeceu às diretrizes da Resolução 466, de 2012, do Conselho Nacional de Saúde e foi aprovado pelo Comitê de Ética em Pesquisa da Universidade Federal de São João Del Rei sob parecer de no 640.010 (BRASIL. Ministério da Saúde, 2012).

\section{Resultados}

\subsection{Necessidades informacionais de gestores da Rede Hiperdia Minas}

A necessidade de informação dentro da Rede Hiperdia ocorre prioritariamente pelo fato de que os gestores são impulsionados a "saber sobre as portarias [...] eu quero saber todas as portarias relacionadas ao programa respira minas, então, eu entro e vejo todas." (P1).

O processo de custeio e pagamento por procedimentos adotado desde o início da criação da Rede Hiperdia Minas também norteia a necessidade de informações, principalmente pelo fato de que "tudo é supervisionado [...] eles recebem o benefício pra contratação e manutenção desses profissionais [...] isso tem que ser seguido. Se não é seguido, eles vão perdendo pontos [...] e isso diminui o retorno financeiro $[\ldots]^{\prime \prime}(\mathrm{P} 1)$.

Outro despertamento pela necessidade de informações ocorre quando se precisa de "[...] informações clínicas pra poder direcionar o nosso trabalho [...] informação judicial, informação de assistência farmacêutica e que a gente utiliza também pra pautar [...]" (P4).

\subsection{Fontes e buscas de informações}

Em relação às fontes de informações, percebe-se que os gestores reconhecem as "pessoas" como fontes para a sua satisfação de necessidades informacionais: "Aqui na secretaria mesmo tem algumas pessoas que são referências nessas questões de publicações e informações" (P4). Os gestores reconhecem que o fato de outros profissionais estarem a mais tempo envolvidos com o programa Hiperdia, isto Ihes transforma em fontes de informação confiáveis: "[...] eu ainda 
tenho muitas dúvidas, então eu sempre recorro aos outros colegas que estão mais tempo no projeto." (P1).

Esta ênfase nas pessoas como fontes de informação também revela certa dependência das mesmas, como fontes seguras:

A gente tá até precisando de um consultor [...]" (P3). Outro entrevistado enfatiza: "desde a saída do Dr, hoje não temos nenhum outro médico pra fazer essa consultoria. [...] a gente segue, tudo que ele deixou [...] Isso meio que acéfalos (risos) $[\ldots](P 2)$.

Se por um lado as pessoas são reconhecidas como fontes confiáveis de informação gerando certa dependência, por outro há situações envolvendo as pessoas que influenciam o comportamento informacional. Primeiramente, os entrevistados apontam "A rotatividade das pessoas é muito grande e muitas vezes no município essa rotatividade é muito maior, perde-se muitas informações [...]" (P2). Com a alta rotatividade em alguns pontos da rede Hiperdia, gera-se a necessidade de se fazer novas capacitações a todo o tempo: "[...] chegam novos contratados e aí você tem que repassar o processo todo de novo e tirar algumas dúvidas." (P8). Além disso, o fluxo de informações entre as pessoas na rede Hiperdia acaba sendo prejudicado: "[...] tem esse rodízio de pessoas do município, saem, não passam pro outro que vai ficar, o outro chega sem saber nada $[\ldots]^{\prime \prime}$ (P9).

O acúmulo de funções devido à falta de profissionais é outra situação relacionada às pessoas, que fragilizam o trâmite das informações dentro da estrutura organizacional na rede Hiperdia: "[...] sou a referência também na saúde do idoso, saúde do homem, práticas integrativas complementares e o centro Hiperdia... [...] não tem como ficar organizando as informações. Muita falta de servidor, falta de profissionais..." (P9). Além disso, algumas informações são centralizadas em pessoas que acumulam vários cargos, e na sua ausência, a disseminação da informação é prejudicada: "[...] Às vezes a F. está com mais de uma coordenação, então assim por algum motivo, algum problema de saúde ela não vem, os processos (relatórios) ficam agarrados $[\ldots]^{\prime \prime}(\mathrm{P} 8)$.

A indicação política para ocupação de cargos é outra situação, também relacionada às pessoas, que compromete o trâmite das informações na rede Hiperdia. Para os participantes "[...] vem assim um secretário, por indicação política, que não entende, que não é da área da saúde e não sabe nem como repassar as informações, e não repassa[...]" (P9). Neste sentido gera-se "Outro problema [...] o desconhecimento desse secretário sobre o programa[...]" (P4).

Os entrevistados também reconheceram que algumas pessoas "gestores", participantes da rede Hiperdia, não cumprem o seu papel de disseminar as informações do Programa em seu município. "[...] às vezes quando a secretária municipal não vai, manda um representante, manda 
um adjunto [...] às vezes na nossa frente ele fala, não, vou resolver, vou passar estas informações, tá certo, mas depois não faz [...]" (P3).

Além das pessoas como fontes de informação, as "linhas guias" e "diretrizes governamentais" são utilizadas como fontes de informação: "Nós baseamos na linha guia [...] é o direcionamento do funcionamento do centro, de como o serviço tem que ser direcionado, como ele é implantado, e quais as diretrizes que tem que ser seguidas." (P1). Em relação às diretrizes governamentais, outro entrevistado enfatiza: "[...] nós temos informações de publicações do Ministério da Saúde. A gente utiliza essas informações pra incrementar as nossas políticas [...]" (P2).

Além das fontes observadas, há também a criação de meios e canais de comunicação internos, que propõem dinamizar e otimizar as tarefas. Sendo citadas como: "planilhas eletrônicas" (P3), "quadros de aviso", "Procedimentos de Operação Padrão (POP)"(P2).

Finalmente, ressalta-se que não existem bibliotecas na rede Hiperdia, fontes de informação importantes, para serem utilizadas pelos gestores: "Aqui (na SES) tem biblioteca? Não. [...]" (P8), e as que existem nos CHDM são pessoais "eu tenho a minha particular que eu sempre trago é... da minha casa. Então tudo que é publicação que eu possa ter acesso e que possa beneficiar o centro eu compro por conta própria mesmo." (P5).

\subsection{Análise das informações pelos gestores para tomada de decisões na rede Hiperdia Minas}

Os gestores relataram que as informações provenientes dos CHDM e disseminadas até a SES/MG são submetidas a "uma análise, uma avaliação [...]" (P1). Entretanto, entendem como "análise" o processo de "confrontar as informações sobre a produção dos CHDM registradas em relatórios", com as "supervisões" feitas, por gestores da SMS ou SES in loco, nos CHDM, onde são constatadas "não conformidades [...]" (P3). Assim, um entrevistado entende o processo analítico das informações: "Quantas consultas de cardiologia o centro realizou? Quantas pra cada município de abrangência? [...] Quantos exames de mapa, de holter, de eletro? [...] quantas reuniões de equipes?" (P3). Constata-se assim, um determinismo burocrático de produção de indicadores, esta é a informação que deve ser registrada e disseminada visto que está atrelada às pontuações e alcance das metas gerando o retorno financeiro ao CHDM: "[...] Eles tem nossa supervisão que tem pontuações. E eu acho que é o primeiro programa onde ele é supervisionado, pontuado e isso impacta diretamente no retorno financeiro que o centro recebe". (P1).

Apenas um dos gestores citou a utilização de um método, o PDCA, mas relacionado à gestão do seu cotidiano de trabalho e não especificamente voltado para sistematizar a crítica e análise de informações: "[...] a gente trabalha com o PDCA então [...] essa avaliação ela é frequente." (P5). 
Os gestores citam as reuniões e capacitações como momentos para análise das informações, mas, novamente, entendem a "análise de informações" relacionada à produtividade e pactuações entre as várias instâncias que compõem a rede: "[...] a gente assim reuni muito, mas para fechar produção. (P5). Outro entrevistado enfatiza: "[...] tem as reuniões onde são pactuadas quantas consultas, quantos exames cada município tem direito $[\ldots]^{\prime \prime}$ (P2).

\subsection{Disseminação das informações na rede Hiperdia Minas}

Há gestores que reconhecem a necessidade de tecnologias para gestão e disseminação da informação: "A gente sente muita falta de um sistema de informação pra gerenciar o centro. [...] muita coisa é feita manualmente $[\ldots]^{\prime \prime}$ (P2). Por não ter um sistema de informação informatizado assim se procede: "[...] eles enviam a publicação (informação), por e-mail, mas se você guardou bem, se você não guardou amém, [...]" (P4). A criação de um prontuário eletrônico também aparece como um anseio, diante da dificuldade na coleta de dados direto de prontuários manuscritos: "[...] a gente não consegue dados compartilhados em atendimento de prontuários físico então a gente precisa de prontuário eletrônico nos municípios pra que a gente garanta uma assistência eficaz [...]" (P4).

A motivação dos gestores com o programa Hiperdia, pelo seu reconhecimento e efetividade, emergiu nos discursos como um fator de estímulo à disseminação de informações entre os CHDM e em outras instâncias: "o retorno dele (o programa Hiperdia) é excelente [...] nós recebemos vários convites, eu não sei se foi Goiânia [...] nossa coordenadora foi para apresentar o projeto [...]" (P1).

Apesar da motivação de alguns gestores para a disseminação da informação, há o reconhecimento da retenção de informações em alguns pontos da rede: "[...] eles falam... eu já repassei essa informação para a regional e aí, a regional não repassa para a gente [...] tem essa questão da informação... ela para" (P8).

A tomada de decisões foi reconhecida como uma atividade que poderia ser feita em conjunto (entre os vários níveis da rede): "[...] acho que a decisão tem que ser tomada em conjunto entre o nível central e a unidade regional" (P4). Entretanto, os discursos remetem ao entendimento de que as decisões, predominantemente, estão atreladas ao nível central (SES/MG) e são repassadas aos demais níveis da rede: "A decisão tem que ser passada por ela (coordenadora) nem que seja só pra cuspir as informações [...] todas as decisões importantes que foram tomadas dentro da secretaria vão ser passadas para a regional por vídeo conferência" (P4). 


\subsection{A qualidade das informações}

No contexto da tomada de decisões, os gestores reconhecem que a baixa qualidade das informações na rede Hiperdia coloca em risco o processo de decidir de forma assertiva:

[...] a gente precisa de informações mais claras [...] pra que a gente tome as decisões com segurança [...] algumas decisões a gente ainda pratica ações em cima de uma corda bamba [...] isso ainda deixa em risco a coordenação no serviço de modo geral $[\ldots]$ (P4).

Destacaram o preenchimento inadequado de relatórios: "[...] alguém preenche alguma coisa errada nesses dados. [...]" (P8). Apontaram a duplicidade de informações: "às vezes a gente no mesmo setor consegue duas informações, mas diferentes sobre determinada ação [...]" (P2). E até mesmo há a dificuldade de encontrar as informações necessárias dentro da rede Hiperdia: "[...] eu já tive assim dificuldade de encontrar informação [...] para dar continuidade ao trabalho [...]" (P1). Além disso há perda de informações: "[...] acho que, talvez, até um banco de dados geral da secretaria que a gente pudesse consultar essas publicações, elas se perdem" (P4).

\section{Discussão dos resultados}

As necessidades informacionais, dimensão inicial do comportamento informacional, observadas entre os gestores da rede Hiperdia são influenciadas pela necessidade de cumprir as diretrizes do programa e de produzir informações sobre a produtividade e alcance de metas atreladas a financiamentos. Nesta óptica, não é o simples acesso dos gestores aos relatórios, formulários, portarias e outras normativas que irão despertar a atenção, serem reconhecidos e assim potencializar a necessidade de sua utilização. Mas a informação discutida, debatida e consensuada é que tem maior potencial de retenção e compreensão (LONG; CURTIS, 2015; WILSON, 2000). O que ocorre no caso da rede Hiperdia é que as principais informações são emanadas das normativas que o regulamentam, e há indícios de pouca participação coletiva na criação e avaliação destas regulamentações. Nessa lógica desencadeia-se um uso passivo das informações, o que dificulta um olhar sistemático para outras necessidades informacionais que poderiam contribuir para a gestão da rede.

Esta opção burocratizada da rede Hiperdia pode até ser um modelo possível para o programa, pois visa o controle, a estabilidade e a coesão. Porém é necessário suplantar o risco de que isto seja uma burocratização excessiva das atividades relacionadas à informação e ao conhecimento na rede, o que pode desencadear certo empobrecimento do conhecimento tácito existente (DOURADO, 2007). Presume-se que não há uma definição 
clara de quais são as necessidades de informações, além da norma, que estes gestores possuem para administrar o seu trabalho. Isto torna o comportamento informacional assimétrico (WILSON, 1981). A necessidade informacional tipificada como cognitiva, afetiva e situacional deve ter uma finalidade, um propósito e um valor de uso. Devido ao seu caráter predominantemente subjetivo é preciso "motivar" a sua enunciação (WILSON, 1981).

Várias fontes de informações foram reconhecidas pelos gestores. Dentre elas destacaram-se os profissionais que trabalham na prática com Hiperdia e se tornam referência enquanto fontes de informação confiáveis e revelou-se certa dependência das mesmas para o desenvolvimento das atividades na rede Hiperdia. Este comportamento de buscar informações em pessoas pode elucidar tentativas de soluções e tomada de decisões mais rápidas (PEREIRA, 2011). Também, pode revelar que há um conhecimento tácito emanado destas pessoas que auxilia no cotidiano de trabalho (LEMOS; JOIA, 2012). Originário das experiências pessoais, da dialogicidade e das interações sociais, o conhecimento tácito precisa ser compartilhado (HUANG; HSIEH; HE, 2014), e isto precisa ser socializado na rede Hiperdia Minas.

O comportamento de disseminar informações entre as esferas de gestão (SES, SRS, SMS, CHDM) segue um fluxo vertical onde a SES define uma norma a ser difundida e cumprida na Rede Hiperdia. No sentido contrário, o CHDM e a SMS, produzem e disseminam informações que comprovem o cumprimento da norma garantindo assim a continuidade do recebimento de recursos. Alguns obstáculos foram destacados na disseminação das informações: a retenção de informações em alguns pontos da rede; a falta de autonomia na tomada de decisões; a burocratização excessiva dos processos internos; baixa qualidade das informações; desconhecimento do programa em algumas instâncias; ausência de sistemas informatizados.

Estes achados sugerem que o compartilhamento de informações na rede Hiperdia seja incipiente ou até mesmo ausente, pois, as trocas de informações são involuntárias, obedecendo ao cumprimento dos compromissos legalmente instituídos, sem qualquer pro-atividade. Informações e conhecimentos precisam ser trocados e usufruídos por diferentes usuários com objetivos estratégicos e centrados nos valores da organização. Isso porque a transferência de conhecimento não é simplesmente o reconhecimento da existência de novas informações, mas também a adoção de conhecimento prático e mudanças de comportamento no cotidiano (CIHR, 2012).

Uma potencialidade que emergiu nos discursos dos gestores e que necessita ser valorizada foi 0 fato de se sentirem motivados com o Programa Hiperdia. Relataram que sentiram-se satisfeitos com o sucesso do programa, e desta feita, são motivados a disseminar informações que comprovam este sucesso. Para Alves e Barbosa (2010) a motivação é um fator que não deve ser ignorado quando da necessidade de potencializar o compartilhamento informacional no ambiente organizacional. 
Em relação à análise das informações e seu uso para a tomada de decisões na rede Hiperdia, verificou-se que estão centrados, predominantemente, na finalidade de fiscalizar o cumprimento das diretrizes que normatizam o programa. Assim, as informações provenientes dos CHDM são analisadas a partir da avaliação do cumprimento ou não das metas definidas anteriormente, bem como a tomada de decisões é norteado por este mesmo princípio. Além disso, algumas decisões são tomadas no patamar mais alto do nível hierárquico, na SES, com pouca ou sem participação coletiva no debate destas decisões e proposições. Não emergiu nos discursos dos gestores um processo sistemático de análise das informações voltadas para decisões locais, onde as atividades do programa se desenvolvem. Mesmo por que o fluxo informacional é caracterizado por uma verticalização, onde situam de um lado os coletadores de informações (municípios e CHDM), comprovando a execução das diretrizes do programa, e do outro lado os avaliadores do cumprimento das mesmas normativas (SRS e SES/MG). Esta conformação do processo analítico e de tomada de decisões pode enfatizar excessivamente a produção de informações justificando o cumprimento da norma, bem como pode ocultar a possibilidade de uso das informações para outras decisões locais que também são necessárias e sem descartar a possibilidade de influências políticas (WILSON, 2010).

Estas constatações remetem a um modelo político de informação onde a centralização das informações e conhecimentos ainda é predominante (WILSON, 1981). Outros autores endossam esta afirmativa quando apontam que no país, e mais especificamente na saúde, há um modelo político de informação hegemônico que canaliza os fluxos informacionais no sentido de alimentar as instâncias superiores (CAVALCANTE et al., 2015). Por outro lado, a descentralização das informações voltadas à alimentação dos níveis mais locais (municípios) ainda é incipiente, bem como o uso destas informações neste contexto é fragilizada (CAVALCANTE, 2011). Neste sentido, estabelecer uma política de informação que incentive o comportamento de análise das informações, o seu uso e a tomada de decisões voltadas também para o contexto local é fundamental.

\section{Considerações finais}

O presente estudo analisou o comportamento informacional de gestores da rede Hiperdia Minas em relação ao cotidiano de trabalho. Nesse sentido, os gestores submetem as informações provenientes do programa a análise e avaliação; buscam as informações em legislações e linhas guias e, principalmente, em pessoas que são consideradas referências no programa. Isso, muitas vezes, compromete o trâmite das informações na rede Hiperdia devido a rotatividade de profissionais, sobrecarga de trabalho e confiabilidade das informações.

Há necessidade de acompanhamento e administração do comportamento informacional na rede Hiperdia Minas, além do ensejo por 
romper com um modelo organizacional burocratizado, centrado na norma e que visa principalmente o controle, mas que pode reduzir a importância das informações e conhecimentos produzidos.

É preciso desenvolver pesquisas que definam as necessidades de informações, além da norma, que os gestores da rede Hiperdia possuem para administrar o seu trabalho local; identificar e desenvolver as competências informacionais destes gestores, bem como, estudos de inovação e desenvolvimento tecnológicos voltados para o desenvolvimento de um sistema de informação/prontuário ou registro eletrônico integrado, capaz de auxiliar a gestão da informação e do conhecimento da rede Hiperdia também são bem-vindos. Enfim, ainda são necessários estudos voltados para a elaboração, viabilidade e legitimação de uma política de informação para toda a rede Hiperdia.

Reconhece-se que os resultados deste estudo não podem ser generalizados devido ao referencial metodológico utilizado. São aplicáveis ao contexto da rede Hiperdia Minas.

\section{Referências}

AKAICHI, T.; MANABE, V. M. M.; BARTALO, L.; ARAÚJO, C. A. A. Comportamento informacional no uso de sistemas de informação: o caso do Sicor. Biblos: Revista do Instituto de Ciências Humanas e da Informação, v. 27, n. 2, p. 31-46, jul./dez. 2013.

ALBINI, C. M. N.; FILHO, E. R. Uso da informação como apoio à decisão dos gestores da saúde pública em um hospital universitário do Paraná um estudo de caso. Rev. Saúde Públ. Santa Cat., Florianópolis, v. 8, n. 2, p. 71-85, maio/ago. 2015.

ALVES, A; BARBOSA, R. R. Influências e barreiras ao compartilhamento da informação: uma perspectiva teórica. Ci. Inf., Brasília, v. 39, n. 2, p. 115128, maio/ago. 2010.

BARDIN, L. Análise de conteúdo. Lisboa: Edições 70, 2011.

BRASIL. Ministério da Saúde. Conselho Nacional de Saúde. Resolução no 466, de 12 de dezembro de 2012. Brasília, 2012. Disponível em: <http://www.conselho.saude.gov.br/web_comissoes/conep/index.html>. Acesso em: 26 dez. 2014.

BYYNY, R. L. The data deluge: the information explosion in medicine and science. Pharos Alpha Omega Alpha Honor MedSoc., v. 75, n. 2, p. 2-5, 2012.

CANADIAN INSTITUTES OF HEALTH RESEARCH (CIHR). Guide to knowledge Translation Planning at CIHR: integrated and end-of-grant approaches. Ottawa: CIHR, 2012.

CAVAlCANTE, R. B. Sistema de Informação da Atenção Básica (SIAB) como instrumento de poder. 2011. 216f. Tese (Doutorado em Ciência da Informação) - Escola de Ciência da Informação, Universidade Federal de Minas Gerais, Belo Horizonte, 2011. 
CAVALCANTE, R. B. et al. Panorama de definição e implementação da política nacional de informação e informática em saúde. Cad. Saúde Pública, Rio de Janeiro. v. 31, n.5, p. 960-970, 2015.

$\mathrm{CHOO}, \mathrm{C} . \mathrm{W}$. Closing the cognitive gaps: how people process information. Financial Times of London; Masterning Information Management, v. 8, p. 6-10, mar. 1999.

DAVENPORT, T. H. Ecologia da informação. São Paulo: Futura, 1998.

DOURADO, M. L. G. O tácito como conhecimento e seu modo de uso no labirinto organizacional contemporâneo. 2007. 188f. Tese (Doutorado em Ciência da Informação) - Escola de Ciência da Informação, Universidade Federal de Minas Gerais, Belo Horizonte, 2007.

EK, S. Gender differences in health information behaviour: a finnish population-based survey. Health Promot Int., v. 30, n. 3, p. 736-45, 2015.

FLANAGAN, J.C. The critical incident technique. Psychology Bulletin, v. 51, n. 4, p. 327-358, 1954.

FRANÇA, L. D. O comportamento informacional dos profissionais médicos e enfermeiros do Programa Saúde da Família (PSF). Sistema Único de Saúde (SUS). Dissertação. 2002. 160f. Dissertação (Mestrado em Ciência da Informação) -Universidade Federal do Piauí; Universidade Federal de Minas Gerais, 2002.

GASQUE, K. C. G. D.; COSTA, S. M. S. Evolução teórico-metodológica dos estudos de comportamento informacional de usuários. Ci. Inf., Brasília, v. 39 n. 1, p. 21-32, jan./abr. 2010.

GTISP; ABRASCO. Plano Diretor para o Desenvolvimento da Informação e Tecnologia de Informação em Saúde: PlaDITIS 2013-2017. Brasília: ABRASCO, jun. 2013. [2a Versão].

HESSELBEIN, F.; GOLDSMITH, M.; BECKARD, R. O líder do futuro: visões estratégicas e práticas para uma nova era. 2. ed. São Paulo: Futura, 1996.

HUANG, X; HSIEH, J. J.; HE, W. Dissimilarity expertise and creativity: the contingent roles of tacit and explicit knowledge sharing. J Appl Psychol., $\mathrm{v}$. 99, n. 5, p. 816-30, 2014.

KUHLTHAU, C. C. Inside the search process: Information seeking th user's perpective. Journal of The American Society for Information Science, v. 42 , n. 5, p. 361-371, 1991.

LEMOS, B.; JOIA, L. A. Fatores relevantes à transferência de conhecimento tácito em organizações: um estudo exploratório. Revista Gestão e Produção, São Carlos, v. 19, n. 2, p. 233-246, 2012.

LONG, A. C.; CURTIS, J. R. Enhancing informed decision making: is more information always better? Crit Care Med., v. 43, n. 3, p. 713-4, 2015. 
MARTÍNEZ-SILVEIRA, M. S. A informação científica na prática médica. 2005. 194f. Dissertação (Mestrado em Ciência da Informação) Universidade Federal da Bahia, Salvador, 2005.

MARTÍNEZ-SILVEIRA, M. S.; ODDONE, N. Necessidade e comportamento informacional: conceitos e modelos. Ci Inf., Brasília, v. 36, n. 1, p. 118127, maio/ago. 2007.

MENDES, E. V. As redes de atenção à saúde. Brasília: Organização PanAmericana de Saúde, 2011.

MINAS GERAIS. Secretaria Estadual de Saúde. Resolução n. 2.606, de 7 de dezembro de 2010. Institui o Programa Hiperdia Minas e dá outras providências. Disponível em: $<$ http://www.saude.mg.gov.br/images/documentos/Resolucao\%202606 10.pdf>.

Acesso em: 26 dez. 2014.

MINAS GERAIS. Secretaria Estadual de Saúde. Resolução n. 4243, de 19 de março de 2014.2 Disponível em: <http://www.saude.mg.gov.br/images/documentos/resol\%C3\%A7\%C3\% A3o_4243.pdf>. Acesso em: $26 \mathrm{dez} .2014$.

MINAYO, M. C. S. Análise qualitativa: teoria, passos e fidedignidade. Ciência e Saúde Coletiva, v. 17, p. 621-626, 2012.

MIRANDA, S. V. Identificando competências informacionais. Ciência da Informação, Brasília, v. 33, n. 2, p. 112-122, maio/ago. 2004.

NOGUEIRA, G. D.; NEVES, J. T. R. Estratégia para a gestão da informação no programa saúde da família do governo brasileiro. $R$ eletr estrat neg., $v$. 2, n. 1, p. 1-24, 2009.

ORGANIZAÇÃO PAN-AMERICANA DE SAÚDE (OPAS). Redes integradas de servicios de salud: conceptos, opciones de política y hoja de ruta para su implemntación em las Americas. Washington: OPAS, 2010.

PATEL, S; DOWSE, R. Understanding the medicines information-seeking behaviour and information needs of South African long-term patients with limited literacy skills. Health Expect., v. 18, n. 5, p. 1494-507, 2015.

PEREIRA, F. C. M. Comportamento informacional na tomada de decisão: proposta de Modelo Integrativo. 2011. 232f. Tese (Doutorado em Ciência da Informação) - Universidade Federal de Minas Gerais, Belo Horizonte, 2011.

RODRIGUES, C. Z. A necessidade de informação dos conselheiros de saúde. 2009. 208f. Tese (Doutorado em Ciência da Informação) Universidade Nacional de Brasília, Faculdade de Economia, Administração, Contabilidade e Ciência da Informação e Documentação. Departamento de Ciência da Informação e Documentação, Brasília, 2009.

SANTOS, S. A. O comportamento informacional dos trabalhadores da saúde que atuam no Programa de controle da hanseníase do estado do 
Paraná. 2011. 98f. Dissertação (Mestrado em Gestão da Informação) Universidade Estadual de Londrina, Londrina, 2011.

SCHAEFER, N. R. Modelo para analisar o perfil profissional de um gerente. 2005. 325f. Dissertação (Mestrado em Engenharia de produção) - UFSC, Florianópolis, 2005.

TAGA, V.; BLATTMAN, U. Comportamento informacional em teses e dissertações na ciência da informação no Brasil entre 2007-2012: Revisão de literatura. Revista Electrónica de Bibliotecología, v.1, n. 47, p. 31-51, 2012.

WILSON, T. D. Information behaviour: an interdisciplinary perspective. Information Proceeding and Management, v. 33, n. 4, p. 551-572, 1997.

WILSON, T. D. Human information behavior. Informing Science, v. 3, n. 2, p. 49-53, 2000.

WILSON, T. D. On user studies and information needs. Journal of Documentation, v. 31, n. 1, p. 3-15, 1981.

WILSON, T. D. Fifty Years of Information Behavior Research. Bulletin of the American Society for Information Science an Techinology, v. 36, n. 3, February/March 2010.

YIN, R.K. Estudo de caso: planejamento e métodos. 5. ed. Porto Alegre: Bookman, 2015.

ZARDO, $\mathrm{P}$; COLLIE, A. Type, frequency and purpose of information used to inform public health policy and program decision-making. BMC Public Health, v. 15, n. $381,2015$. 